May 2020

\title{
Online Community for Librarian Researchers: Experience of Academic Librarians
}

Lili Luo

San Jose State University, lili.luo@sjsu.edu

Follow this and additional works at: https://scholarworks.sjsu.edu/ischoolsrj

Part of the Archival Science Commons, Cataloging and Metadata Commons, Collection Development and Management Commons, Information Literacy Commons, Museum Studies Commons, Scholarly Communication Commons, and the Scholarly Publishing Commons

\section{Acknowledgements}

a

\section{Recommended Citation}

Luo, L. (2020). Online Community for Librarian Researchers: Experience of Academic Librarians. School of Information Student Research Journal, 10(1). https://doi.org/10.31979/2575-2499.100102 Retrieved from https://scholarworks.sjsu.edu/ischoolsrj/vol10/iss1/2

This article is brought to you by the open access Journals at SJSU ScholarWorks. It has been accepted for inclusion in School of Information Student Research Journal by an authorized administrator of SJSU ScholarWorks. For more information, please contact scholarworks@sjsu.edu. 


\section{Online Community for Librarian Researchers: Experience of Academic Librarians}

\section{Keywords}

research, librarians, academic librarians, online community, community, scholarship, data, data analysis, survey, survey analysis, IMLS

\section{Acknowledgements}

\section{a}

\section{About Author}

Dr. Luo received her PhD from the School of Information and Library Science at University of North Carolina at Chapel Hill. Her primary areas of teaching and research interests include information access and services in the digital age, research methods, academic librarianship, and health information services. She documents her musings about research and teaching on her blog titled "Formalized Curiosity". Lou also serves as the coordinator for the SJSU iSchool Center for Information Research and Innovation (CIRI). 
In academic libraries, librarian research and scholarship are emphasized. As early as 1972, ACRL's “Joint Statement on Faculty Status of College and University Librarians" highlighted librarians' research roles in both professional interests and work responsibilities (Perkins \& Slowik, 2013). Research serves to create new knowledge and therefore contribute to the growth of academic librarianship, and it is needed to "improve problem solving and decision making in the workplace, to make professional practitioners critical consumers of the research literature, and to better equip librarians to provide optimal information services to researchers in other fields" (Powell, Baker, \& Mika, 2002).

Given the well-acknowledged significance of research in academic libraries, from 2014 to 2019, Institute of Museum and Library Services (IMLS) funded a program titled "Institute for Research Design in Librarianship (IRDL)". This program provides continuing education opportunities for a selected group of academic librarians to enhance their research skills and output, and to increase the scope and value of academic library research. It also seeks to increase the research confidence of participants by providing both mastery experiences and social persuasion. According to Bandura (1994), mastery experiences build confidence through success and provide an individual with the ability to persevere in the face of obstacles, which is especially important in performing difficult tasks. Social persuasion consists of structuring situations in which an individual receives encouragement and experiences success in working through challenges. The centerpiece of IRDL is a nine-day summer research workshop, where academic and research librarians develop the skills necessary to complete a research study of their design during the coming year. IRDL's learning objectives include:

- Write effective research questions and hypotheses

- Choose an appropriate research design for a library science study

- Conduct a literature review

- Explain the conceptual logic behind various data collection approaches and describe the rationale for selection of specific methods

- Identify appropriate sampling strategies for research projects

- Use and apply commonly used qualitative data collection methods

- Assess and apply different qualitative data analysis options

- Design and implement a survey

- Understand survey data analysis

- Explain various analytic options for surveys

- Understand basic principles of mixed methods research design

- Choose an appropriate research dissemination forum

- Write and disseminate an effective research report

- Access and participate in the Institute virtual community and related networks for support during the research process

Participants' collaborative learning experience during the time of IRDL reinforces the learning goals and begins to create a community of practice. In the following year, ongoing support via an online community is provided to assist IRDL participants in conducting and disseminating their research. 
Curious to learn the role of online communities in helping librarian researchers connect with each other, and support each other in their research process, my colleagues and I decided to examine this online community of IRDL participants. We conducted content analysis of participants' public tweets related to IRDL as well as their posts on the private "IRDL Scholars" Facebook group page. We also administered an online survey about their perceptions of the Facebook group as a platform to meet the needs of their online community.

Most of the IRDL participants were involved in the online community. They exhibited a variety of posting behavior, suggesting the participants have different patterns of engaging in the online community - some may be more active in initiating posts, and others may feel more comfortable with just responding to what is posted; and some may prefer one social media venue over another. The discrepancies of preferences were also reflected in their responses to the online survey, where some appreciated the use of a social media platform like Facebook to host the online community, and some others felt a platform separate from social media would have been more appropriate. Given the varying behavior and preferences among individuals, when designing online communities for librarian researchers, it would be helpful to investigate what potential participants need or desire in terms of the venue, form and set-up of the online community. As the community develops, the participants' needs and desires may also evolve; thus it is important to provide a channel for them to voice their input, based on which the design of the online community can continue to improve. In their discussion of online communities' life cycle, Iriberri and Leroy's (2009) identified user-centered design and evolution as a success factor at the creation stage of an online community.

It is worth noting that the IRDL online community participation peaked in the first month after the IRDL onsite training. After that, both Facebook and Twitter posts had been dropping. This could be attributed to the fact that the community was relatively small. Iriberri et al. (2009) when discussing the growth stage of the online community life cycle, pointed out the importance of reaching a critical mass and integrating new members. But both conditions were lacking in the IRDL online community, which may have contributed to the decline in participation.

In the online survey, the majority of the respondents indicated that they both identify with what the group represents - librarian scholars who conduct and/or disseminate quality research, and have personal connections with some members of the group. According to Ren, Kraut, and Kiesler (2007) both common identity and common bond theory apply here. Common identity in the online context implies that members feel committed to the online community's purpose or topic, and common bond suggests that members feel socially or emotionally attached to particular members of the online community. On one hand, the participants have a shared identity the online community is dedicated to - librarian researcher; on the other hand, their shared IRDL experience serves as a bond that provides personal connections in the online community. When designing online communities for librarian researchers, it is important to understand members' attachment to the group when integrating new members and make design decisions accordingly. If the community is more identity based, efforts should be made on helping 
newcomers navigate through information traffic, understand community norms, and engage in community conversations in meaningful ways. If the community is more bond-based, the focus needs to be on assisting newcomers in connecting with existing members, joining group interactions, and forming lasting relationships with a subset of community members (Ren et al., 2007).

In terms of the content of online posts, Facebook and Twitter had the following overlap - posts related to completing the IRDL research project, announcements about research-related resources and opportunities, posts reminiscing about the IRDL experience, and arrangements of conference attendance and meetups. These four categories provide a glimpse of the popular topics an online community for librarian researchers may be interested in. This knowledge may help online community designers better understand how to initiate and monitor discussions on relevant topics. Iriberri et al. (2009) considered content quality as one of the success factors for the growth stage of the online community life cycle, and knowing what types of content might be appealing to the community is an important first step in ensuring content quality.

Overall the participants were satisfied with different aspects of the online community on Facebook. Their satisfaction with the content of the Facebook posts was the highest, indicating that they were most satisfied with the issues or topics being discussed. Wang, Chen, and Tsai (2012) discovered that member commitment in online communities is heavily influenced by members' issue involvement. This echoes the aforementioned importance of content quality in Iriberri et al. (2009) reinforcing the need to keep community members engaged in the discussion of relevant, meaningful and interesting topics when designing online communities for librarian researchers.

Steuer's (1992) communication model describes how communication occurs not only between one individual and another, but also between individuals and the mediated environment with which they interact. Thus, in online communities, the technology interface perspective is necessary to consider. In the case of the IRDL online community, the participants reported a relatively high level of satisfaction with using Facebook as the online community platform. Still, some of them pointed out its limited functionalities such as the difficulty in archiving, searching and retrieving old posts. When designing online communities for librarian researchers, it is imperative to adopt an interface that meets all the user requirements, and yet is stable, intuitive and easy to use.

In this rapidly changing world, more and more librarians undertake their own research to meet "the need for more information for use in decision making at the managerial level, the need to keep abreast of new knowledge and procedures in this information society, and the need for continuing education and upgraded qualifications" (Jarvis, 1999). Online communities provide opportunities for librarians to interact with each other and support each other in the process of conducting and disseminating research to enhance practices. They offer a sense of camaraderie and belonging, and can help librarian researchers overcome the numerous barriers they face in their research journey. We hope to see more efforts seeking to unearth effective and efficient ways to establish and grow online 
communities for librarian researchers, and more conversations about the role of online communities in assisting librarians' professional growth.

$$
\text { References }
$$

Perkins, G.H. and Slowik, A. (2013). The Value of Research in Academic Libraries. College \& Research Libraries, 74(2), 143-158.

Powell, R.R., Baker, L.M., and Mika, J.J. (2002). Library and Information Science Practitioners and Research. Library and Information Science Research, 24(1), 50.

Bandura, A. (1994). Self-efficacy. In Ramachandran, V.S. (Ed.) Encyclopedia of Human Behavior (pp. 71-81). New York: Academic Press.

Iriberri, A. and Leroy, G. (2009). A Life-cycle Perspective on Online Community Success. ACM Computing Surveys, 41(2). 1-29.

Ren, Y., Kraut, R. and Kiesler, S. (2007). Applying Common Identity and Bond Theory to Design of Online Communities. Organization Studies, 28(3). 377-408.

Wang, Chen, and Tsai, "Investigating Member Commitment to Virtual Communities using an Integrated Perspective," 199-210.

Steuer, J. (1992). Defining Virtual Reality: Dimensions Determining Telepresence. Journal of Communication. 42(4). 73-93.

Jarvis, P. (1999) The Practitioner-Researcher: Developing Theory from Practice. (pp. 7). San Francisco, CA: Jossey-Bass Publishers. 


\begin{tabular}{|l|l|l|l|l|}
\hline $\begin{array}{l}\text { IRDL 2014 Cohort } \\
\text { Member }\end{array}$ & \# of Tweets & $\begin{array}{l}\text { \# of Facebook } \\
\text { Posts }\end{array}$ & $\begin{array}{l}\text { \# of Facebook } \\
\text { Likes }\end{array}$ & $\begin{array}{l}\text { \# } \text { of Facebook } \\
\text { Replies }\end{array}$ \\
\hline Member A & $0(0.0 \%)$ & $13(8.2 \%)$ & $17(3.6 \%)$ & $27(5.0 \%)$ \\
\hline Member B & $0(0.0 \%)$ & $0(0.0 \%)$ & $0(0.0 \%)$ & $0(0.0 \%)$ \\
\hline Member C & $11(4.2 \%)$ & $0(0.0 \%)$ & $2(0.4 \%)$ & $11(2.1 \%)$ \\
\hline Member D & $24(9.2 \%)$ & $21(13.2 \%)$ & $13(2.8 \%)$ & $91(17.0 \%)$ \\
\hline Member E & $21(8.1 \%)$ & $6(3.8 \%)$ & $41(8.7 \%)$ & $30(5.6 \%)$ \\
\hline Member F & $3(1.2 \%)$ & $5(3.1 \%)$ & $17(3.6 \%)$ & $9(1.7 \%)$ \\
\hline Member G & $1(0.4 \%)$ & $0(0.0 \%)$ & $12(2.5 \%)$ & $2(0.4 \%)$ \\
\hline Member H & $1(0.4 \%)$ & $42(26.4 \%)$ & $36(7.6 \%)$ & $126(23.6 \%)$ \\
\hline Member I & $0(0.0 \%)$ & $0(0.0 \%)$ & $0(0.0 \%)$ & $0(0.0 \%)$ \\
\hline Member J & $3(1.2 \%)$ & $4(2.5 \%)$ & $19(4.0 \%)$ & $18(3.4 \%)$ \\
\hline Member K & $17(6.5 \%)$ & $3(1.9 \%)$ & $9(1.9 \%)$ & $4(0.7 \%)$ \\
\hline Member L & $6(2.3 \%)$ & $1(0.6 \%)$ & $8(1.7 \%)$ & $2(0.4 \%)$ \\
\hline Member M & $39(15.0 \%)$ & $5(3.1 \%)$ & $26(5.5 \%)$ & $14(2.6 \%)$ \\
\hline Member N & $0(0.0 \%)$ & $11(6.9 \%)$ & $16(3.4 \%)$ & $29(5.4 \%)$ \\
\hline Member O & $0(0.0 \%)$ & $3(1.9 \%)$ & $33(7.0 \%)$ & $16(3.0 \%)$ \\
\hline Member P & $2(0.8 \%)$ & $0(0.0 \%)$ & $25(5.3 \%)$ & $1(0.2 \%)$ \\
\hline Member Q & $4(1.5 \%)$ & $8(5.0 \%)$ & $31(6.6 \%)$ & $32(6.0 \%)$ \\
\hline Member R & $21(8.1 \%)$ & $2(1.3 \%)$ & $8(1.7 \%)$ & $4(0.7 \%)$ \\
\hline Member S & $56(21.5 \%)$ & $8(5.0 \%)$ & $36(7.6 \%)$ & $50(9.3 \%)$ \\
\hline Member T & $0(0.0 \%)$ & $1(0.6 \%)$ & $7(1.5 \%)$ & $4(0.7 \%)$ \\
\hline Member U & $7(2.7 \%)$ & $2(1.3 \%)$ & $17(3.6 \%)$ & $6(1.1 \%)$ \\
\hline Member V & $15(5.8 \%)$ & $1(0.6 \%)$ & $4(0.8 \%)$ & $14(2.6 \%)$ \\
\hline Member W & $28(10.8 \%)$ & $14(8.8 \%)$ & $7(1.5 \%)$ & $18(3.4 \%)$ \\
\hline Member X & $0(0.0 \%)$ & $0(0.0 \%)$ & $38(8.1 \%)$ & $7(1.3 \%)$ \\
\hline Member Y & $1(0.4 \%)$ & $9(5.7 \%)$ & $49(10.4 \%)$ & $20(3.7 \%)$ \\
\hline Total & $260(100 \%)$ & $159(100 \%)$ & $471(100 \%)$ & $535(100 \%)$ \\
\hline
\end{tabular}

Table 1. Frequency distribution of cohort members' Facebook and Twitter posts 
School of Information Student Research Journal, Vol. 10, Iss. 1 [2020], Art. 2

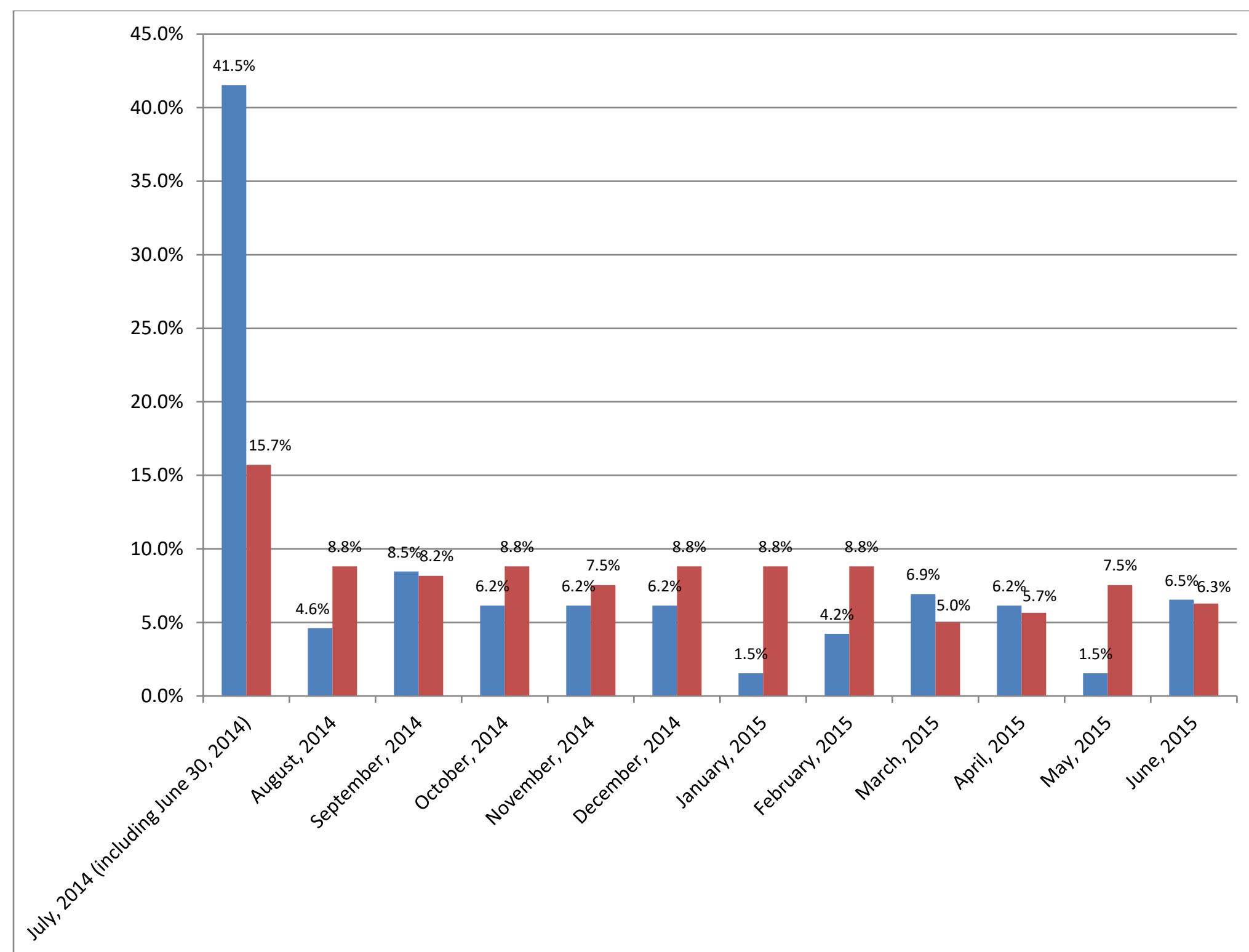

$\%$ of Tweets

$\%$ of Facebook Posts

Figure 1. Monthly distribution of Facebook and Twitter posts 
Luo: Librarian Researcher Online Community: Academic Librarian Experience

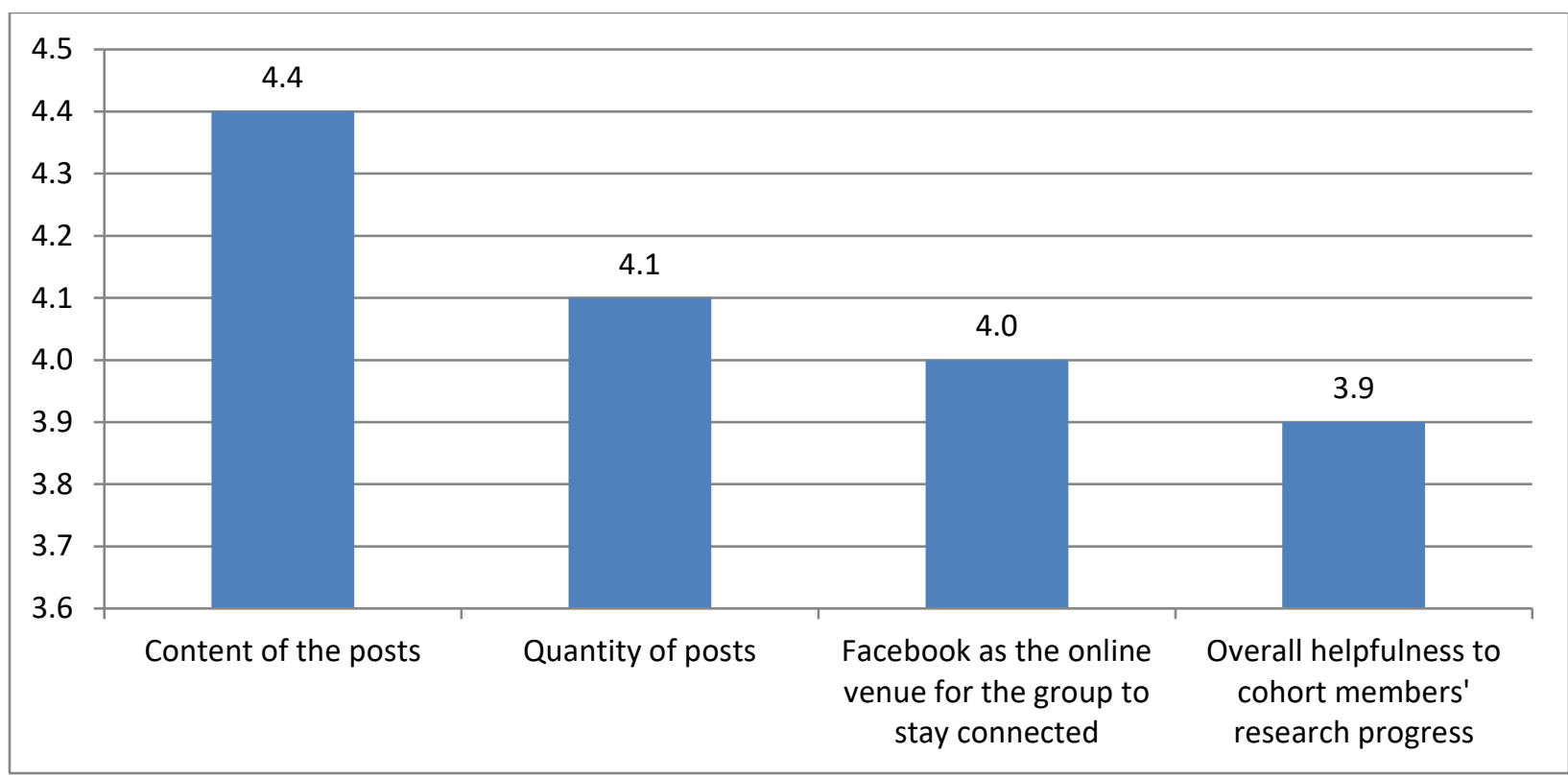

Figure 2. Cohort members' satisfaction with different aspects of the Facebook group 